\title{
AS METODOLOGIAS ATIVAS DE ENSINO E APRENDIZAGEM EM TEMPOS DE PANDEMIA: A UTILIZAÇÃO DOS RECURSOS TECNOLÓGICOS NA EDUCAÇÃO SUPERIOR
}

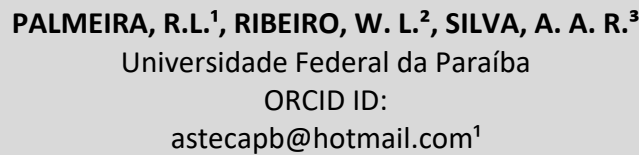

Submetido 24/07/2020 - Aceito 12/11/2020

DOI: $10.15628 /$ holos. 2020.10810

\section{RESUMO}

Este artigo aborda o uso das metodologias ativas como recurso didático a ser aplicado, notadamente no ensino remoto, durante o período de isolamento social, ocasionado em virtude da pandemia da Covid-19, bem como no contexto pós-isolamento social, com a finalidade de promover a formação integral do estudante do nível superior. Focaliza o papel das ferramentas tecnológicas, sobretudo salas de aula e ambientes virtuais, para potencializar o processo de ensino $\mathrm{e}$ aprendizagem centrado no desenvolvimento do pensamento crítico, reflexivo e analítico dos discentes.
Propõem-se como questões de pesquisa: "Que oportunidades de aprendizagem os professores podem propor para o período de ensino remoto? Quais estratégias e metodologias pedagógicas deveriam ser utilizadas?". O objetivo é analisar as estratégias didáticas passíveis de serem utilizadas pelos professores de instituições de ensino superior para dar continuidade aos semestres acadêmicos de forma remota, buscando perceber na literatura o potencial de aplicação das metodologias ativas na prática docente inserida nessa nova modalidade de ensino a distância.

PALAVRAS-CHAVE: Pandemia, Metodologias Ativas, Ensino superior, Ensino a Distância.

\section{ACTIVE TEACHING AND LEARNING METHODOLOGIES IN TIMES OF PANDEMIC: THE USE OF TECHNOLOGICAL RESOURCES IN HIGHER EDUCATION}

\begin{abstract}
This article addresses the use of active methodologies as a didactic resource to be applied, notably in remote education, during the period of social isolation, caused by the Covid-19 pandemic, as well as in the post-isolation context, with the purpose of promoting the integral formation of college students. It focuses on the role of technological tools, especially classrooms and virtual environments, to enhance the teaching and learning process centered on the development of critical, reflective and analytical thinking of students. The
\end{abstract}

following research questions are proposed: "During remote teaching period, which learning opportunities may teachers propose? Which pedagogical strategies and methodologies should be used?". The objective is to analyze the teaching strategies that can be used by teachers from higher education institutions to continue the academic semesters remotely, seeking to perceive in the literature the potential of applying active methodologies in teaching practice inserted in the new distance learning modality. 


\section{INTRODUÇÃO}

O período de isolamento físico nos fez pensar em estratégias para acompanhamento e apoio aos estudantes e para manutenção das atividades didáticas. Alguns chamam de ensino a distância $(E A D)$, outros de ensino online, mas, na verdade, no contexto atual, trata-se de um ensino remoto emergencial. Nesta modalidade não se pretende transformar o ensino presencial em ensino a distância, visto que as estratégias de abordagem didática-pedagógica são diferentes. O professor continua sendo peça chave neste processo de transformação digital na educação e mudanças de paradigmas de ensino e aprendizagem, e as dificuldades existentes consistem em manter os discentes ativos e engajados durante este período de isolamento social. Segundo o escritor americano de educação superior e analista de políticas Kevin Carey: "Ninguém planejou uma migração em massa e abrupta dos cursos superiores de propósito. Mas por conta do Coronavírus, aqui estamos." (CAREY, 2020).

A Organização das Nações Unidas para a Educação, a Ciência e a Cultura (UNESCO) anunciou em 27 de março de 2020 que 850 milhões de alunos, em 102 países, estavam sem aulas. Por esse motivo, surgiu a necessidade de utilização de novas tecnologias de ensino a distância para manter o cronograma de aulas e, até mesmo, repor aulas. A UNESCO, em parceria com organizações multinacionais, está ajudando os países a desenvolver sistemas de aprendizagem a distância com o objetivo de reduzir os impactos da suspensão das aulas e manter o contato social com os alunos. Entretanto, reconhece a dificuldade de atender os estudantes de maneira igualitária, pois em muitos países uma parcela dos alunos não têm acesso à Internet e ou computadores, não há infraestrutura tecnológica.

Nesses países é necessário que as instituições formadoras tomem medidas para minimizar os prejuízos, evitando o abandono ou trancamento de matrículas, e promovam ações de inclusão digital. A UNESCO enfatiza algumas recomendações para garantir que a aprendizagem permaneça sem interrupções durante esse período, dentre elas destacamos: escolher ferramentas digitais mais relevantes; implementar medidas para garantir que os estudantes com necessidades especiais ou de baixa renda tenham acesso a programas de educação a distância, garantindo que ocorra a sua inclusão; priorizar soluções para enfrentamento dos desafios psicossociais com os quais os estudantes possam se deparar no contexto do isolamento.

Nessa perspectiva, diversas Instituições de Ensino Superior (IES) implementaram estratégias didáticas, utilizadas pelos professores para dar continuidade aos semestres acadêmicos de forma remota, evidenciando o potencial de aplicação de metodologias ativas na prática docente inserida nessa nova modalidade de EaD.

A crise pandêmica na educação mundial impactou a todos indistintamente, fazendo surgir a necessidade de ressignificação da prática docente proporcionada pela adoção das novas modalidades de ensino a distância. Elucidou-se uma nova forma de compreender a educação, ampliar e tornar os sistemas educacionais mais abertos e inovadores, embora que de uma maneira impositiva. Assim, além de adotar de recursos tecnológicos, é preciso fornecer subsídios suficientes para engajar os estudantes nos processos de ensino e aprendizagem, através do desenvolvimento 
de atividades acadêmicas dinâmicas e envolventes, como a resolução de problemas, estudos de caso, aprendizagem colaborativa, pesquisa e escrita científica.

É necessário que os docentes pensem um formato online de formação que propicie aos estudantes não apenas a sua participação, mas oportunidades de aprendizagem que aliem três dimensões (Figura 1): a dimensão afetiva, que contempla sua motivação e desejo de aprender, ditando o seu envolvimento com o objeto de estudo e sua percepção de sentido em estudá-lo; a dimensão cognitiva, que refere-se à mobilização intelectual para que ocorra a compreensão e apreensão; e a dimensão comportamental, em outras palavras, as manifestações observáveis de engajamento dos alunos que demonstram o seu saber fazer e colocar em prática aquilo que aprenderam (CÔRTE VITÓRIA et al.2018).



Figura 1: Dimensões do engajamento acadêmico no ensino remoto

Fonte: Côrte Vitória et al. 2018.

Observa-se que alguns professores, ao transferirem suas aulas para os ambientes virtuais acabam por dar mais ênfase aos aspectos didáticos, metodológicos e avaliativos, os quais, embora sejam de fundamental importância, não favorecem o engajamento dos seus alunos. Sendo assim, Côrte Vitória e colaboradores (2018) ressaltam que é importante estar ciente da complexidade dos sujeitos, buscando conhecê-los e identificar suas potencialidades, mapear suas fragilidades e desenhar os desafios como forma de propor percursos pedagógicos que, além de ensinar, consigam suscitar a curiosidade e a criatividade.

Outro ponto importante a ser levado em consideração é o oferecimento de suporte socioemocional aos docentes para enfrentar a pressão extra exercida sobre eles, com a finalidade de proporcionar aprendizado em tempos de crise, bem como apoiar as necessidades emocionais de seus alunos.

Efetuar a adaptação e a criação de materiais didáticos em formato digital, em curto prazo, tem sido um desafio, pois nem todos os professores têm um manejo das tecnologias da informação e comunicação bom o suficiente para utilizar as ferramentas digitais de aprendizado. Empresas como a Google e a Microsoft dispõem de um conjunto de ferramentas digitais e ambientes de 
aprendizagem como: Google G-suite for Education e Big Brain for Education da Microsoft, com soluções para o ensino básico e superior.

Propõem-se questões de pesquisa como: "Que oportunidades de aprendizagem os professores podem propor para o período de ensino remoto? Quais estratégias e metodologias pedagógicas deveriam ser utilizadas?" É importante diversificar as formas de lecionar, as práticas educativas e as modalidades de avaliação utilizadas, além de apresentar novas estratégias de ensino-aprendizagem, como as metodologias ativas, consideradas um novo desafio para a formação de professores.

A metodologia ativa é uma concepção educativa que estimula processos construtivos de ação-reflexão-ação, em que o estudante tem uma postura ativa em relação ao seu aprendizado numa situação prática de experiências, por meio de problemas que lhe sejam desafiantes e Ihe permitam pesquisar e descobrir soluções aplicáveis à realidade. Este artigo analisa como utilizar as novas tecnologias, principalmente a utilização da Internet na educação a distância em tempos de pandemia da Covid-19, bem como o papel do professor como mediador, utilizando as novas tecnologias de forma mais participativa e trabalhando com projetos colaborativos.

\section{REVISÃO BIBLIOGRÁFICA}

\subsection{Pedagogia universitária e metodologias ativas}

As metodologias ativas baseiam-se em formas de desenvolver o processo de aprender, utilizando experiências reais ou simuladas, visando às condições de solucionar, com sucesso, desafios advindos das atividades essenciais da prática social, em diferentes contextos. Segundo Berbel (2011) as metodologias ativas têm o potencial de despertar a curiosidade à medida que os alunos se inserem na teorização e trazem elementos novos, ainda não considerados nas aulas ou na própria perspectiva do professor. As metodologias ativas valorizam os estímulos e sentimentos de engajamento, percepção de competência e de pertencimento, além da persistência nos estudos, entre outras. Logo, têm a intenção de promover a autonomia do aluno e o potencial da área pedagógica.

Dentre as metodologias ativas, podemos mencionar como uma alternativa passível de ser totalmente adaptadas às necessidades do ensino remoto as estratégias de ensino híbrido. De acordo com Valente (2014), com a disseminação das tecnologias digitais de informação e comunicação (TDIC) surgiram várias modalidades de ensino a distância, tais como ensino híbrido, que no contexto usual combina atividades presenciais e à distância.

Segundo Staker e Horn (2012) o ensino híbrido mescla momentos em que o aluno acessa conteúdos e instruções disponibilizados por meio de recursos online e outros em que o ensino ocorre dentro da sala de aula, envolvendo a participação de alunos e professores. Em virtude do isolamento social, os momentos de sala de aula podem ser realizados por meio de vídeo conferências, através de plataformas e servidores online, o que permite manter um momento de contato e interação entre docentes e discentes, mesmo que de forma não-presencial. 
Pelo fato de não serem presenciais, esses momentos de aula devem ser planejados de forma cautelosa pelo docente, com a finalidade de valorizar a participação dos estudantes e viabilizar discussões e momentos em grupos, havendo a possibilidade de abrir diferentes grupos focais, de forma simultânea ou sequencial, para que ocorram as interações interpessoais.

Essa preocupação é consonante com a afirmação de Staker e Horn (2012) acerca da importância da sala-de-aula proporcionar "um processo de ensino e de aprendizagem mais eficiente, interessante e personalizado." Sachetti (2017) define quatro categorias de ensino híbrido: o flex, blended misturado, virtual enriquecido e rotação. Dessas, duas destacam-se quanto ao seu potencial de aplicação adaptada ao ensino remoto, são elas o modelo flex e rotação.

O modelo flex é aquele no qual a atividade principal do processo de ensino aprendizagem consiste no momento de estudo dos conteúdos e instruções de forma online. Nessa proposta, o docente presta apoio presencial de forma flexível e adaptável, conforme necessário, por meio de atividades como instrução de grupos pequenos, projetos de grupo e aulas particulares (SACHETTI, 2017). Adaptando para uma abordagem totalmente a distância, o professor pode orientar a realização de projetos em grupos e agendar, via web-conferência, encontros com as equipes, para que ocorra tanto a instrução destas, quanto o atendimento de questões individuais.

Sachetti (2017) define que modelo rotação é dividido em "quatro subgrupos que proporcionam ao aluno a chance de circular por diferentes modalidades de aprendizagem". Um deles é a sala de aula invertida, modalidade de ensino que é descrita por Bergman e Sams (2016) como uma inversão do que é feito em sala de aula no modelo tradicional de ensino, que agora é executado em casa (como o contato com o conteúdo teórico por meio das leituras e demais materiais de estudo), e o que no modelo tradicional é feito em casa passa a ser realizado em sala de aula (como debates, projetos, trabalhos em grupos, solução de problemas). Portanto, conforme Bergman e Sams (2016), inverter a sala de aula tem a ver com o deslocamento da atenção do professor para o aprendiz e para a sua aprendizagem.

É possível dispor os materiais de estudo não apenas na forma de textos, mas também aproveitar conteúdos áudios visuais já existentes na Internet, conforme indica Moffet (2015), em plataformas como o Youtube e o Vmeo e também blogs voltados para o ensino. Esse autor também indica que, caso o docente não esteja familiarizado com a produção de vídeo aulas próprias, uma alternativa é gravar a sua voz sobre uma apresentação de slides, utilizando tal ferramenta no Microsoft Office PowerPoint.

Para planejamento das aulas em tempo real, uma sugestão é tomar como base a sequência didática utilizada por Melo et al. (2018) para ensino do tema abertura coronária em Endodontia, em que as aulas presenciais foram divididas em quatro etapas sequenciais: a primeira parte, na qual avaliou-se o conhecimento adquirido no estudo prévio por meio da aplicação de teste individual de múltipla escolha; a segunda parte na qual, após a resolução dos testes, os estudantes foram distribuídos em grupos para discussão das respostas individuais, havendo a conferência, a reflexão crítica e a construção de um gabarito único validado; a terceira, na qual era apresentado um casoproblema para contextualização clínica do conteúdo, acompanhado de questões para serem resolvidas pelos estudantes em grupo; o quarto e quinto momentos, que visavam revisar os procedimentos práticos previamente estudados e sua replicação em laboratório. 
Logo, a partir desse exemplo de aplicação da sala de aula invertida, as aulas online instantâneas podem ser dirigidas de forma semelhante, fazendo algumas adaptações. O professor pode dar início fazendo colocações sobre os objetivos de aprendizagem do dia, orientando a aplicação de um questionário desenvolvido em alguma plataforma online, como, por exemplo, o Google Formulários, para testar se o estudo dos conteúdos dispostos foi efetivo para gerar o aprendizado esperado.

Retornando a sala de aula virtual, o professor pode dividir os estudantes em times e dispor de reuniões distintas e simultâneas, entre as quais ele poderá transitar durante um espaço de tempo definido. Num terceiro momento, reunindo todos novamente, discute-se até que se chegue coletivamente a um gabarito correto e validado. No quarto momento, o professor pode propor aos alunos que seja organizada por eles uma exposição de um dos materiais previamente estudados e, retornando a um momento envolvendo todos os discentes e o docente, sejam apresentadas as exposições. Podem ser utilizados também materiais que ainda não foram vistos, de modo a desafiar os alunos a desenvolver um maior senso de trabalho em grupo e uma organização mais disciplinada do tempo.

Os docentes do ensino superior têm um gama de possibilidades metodológicas norteadoras, que possibilitam encontrar a forma mais adequada de aliar as diversas tecnologias disponíveis aos procedimentos didáticos, viabilizados pelas formas de comunicação interpessoal de grupo e as de comunicação audiovisual. Esta é uma tarefa bastante desgastante neste momento, em que são necessárias adequações na pedagogia universitária, tendo em vista a nova realidade de situações adversas das que foram pensadas e planejadas no Currículo adotado nos cursos. É importante que cada docente encontre na sua prática uma forma de sentir, comunicar e transmitir o seu conhecimento, ajudando os alunos a aprender neste novo paradigma da educação de contexto emergencial. Os professores, que agregarem transformações em suas práticas, poderão ser mais eficientes em função das exigências da realidade social e da urgência em ampliar o acesso escolar e cultural da classe menos favorecida, dado o avanço científico e tecnológico.

\subsection{O Ensino a Distância para um novo contexto}

Os impactos ocasionados pela pandemia do novo Coronavírus atingiram o mundo de maneira repentina, necessitando que o processo de ensino e aprendizagem fosse repensado e ressignificado a fim de atender a esse momento de excepcionalidade. Apesar da Educação a Distância ter sido institucionalizada no Brasil com Decreto no 5.622, de 19 de dezembro 2005, que regulamentou a Educação a Distância no ensino superior brasileiro, diversas instituições tiveram que se readaptar, às pressas, a esse novo cenário, para evitar ainda mais prejuízos aos discentes.

Dados da Pesquisa Nacional por Amostragem de Domicílios (PNAD), realizada em 2015 pelo Instituto Brasileiro de Geografia e Estatística (IBGE, 2016), ilustram que aproximadamente 102,1 milhões de pessoas de 10 anos ou mais de idade acessaram a Internet no período de referência da pesquisa em 2015, o que representou um crescimento de 7,1\%, ou 6,7 milhões de usuários, em relação a 2014. Embora tenha ocorrido uma elevação na proporção de internautas, que passou de $54,4 \%$ para $57,5 \%$ do total da população residente no Brasil, tendo as regiões Sudeste, Sul e Centro- 
Oeste registrado proporções acima da média nacional, de $65,1 \%, 61,1 \%$, e $64,0 \%$, respectivamente; nas regiões Norte e Nordeste apenas $46,2 \%$ e $45,1 \%$ das pessoas tiveram esse acesso.

Assim, pensando nos percentuais de pessoas que não tem esse acesso para cada uma das regiões, $34,1 \%$ para a região Sudeste, $38,9 \%$ para o Sul, $36 \%$ do Centro-Oeste, $53,8 \%$ do Norte e $54,9 \%$ da Nordeste; percebe-se que, antes da pandemia, um percentual elevado de residências não tinha acesso à Internet. Por essa razão, o primeiro aspecto a ser levado em consideração quando se fala de ensino remoto é justamente a possibilidade do acesso à rede mundial de computadores interligados.

Ainda nessa pesquisa do IBGE, foram elucidados os principais motivos pelos quais os domicílios não têm acesso à Internet, são eles (IBGE, 2016):

I. Alto custo do equipamento eletrônico necessário para obter o acesso à Internet;

II. Indisponibilidade do Serviço de Fornecimento do acesso à Internet;

III. Alto custo do Serviço de acesso à Internet;

IV. Nenhum dos moradores sabia como utilizar a Internet;

V. Falta de interesse em acessar à Internet.

A PNAD 2015 também constatou que 31,4 milhões de domicílios possuíam microcomputador em 2015, correspondendo a uma redução de 3,4\% em relação ao ano anterior e, desse total, 27,5 milhões de unidades domiciliares tinham computador com acesso à Internet. Com relação a distribuição de domicílios, $46,2 \%$ deles possuíam microcomputador e 40,5\% possuíam microcomputador com acesso à Internet (IBGE, 2016).

Segundo dados fornecidos pela Pesquisa Nacional por Amostra de Domicílios Contínua PNAD Contínua, o tema suplementar Tecnologia da Informação e Comunicação (TIC) nos aspectos de acesso à Internet e à televisão e posse de telefone móvel celular para uso pessoal foi pesquisado pela primeira vez no levantamento de 2016. Os dados da PNAD Contínua TIC 2016, demonstram que: "entre os usuários da Internet com 10 anos ou mais de idade, 94,6\% conectaram-se via celular, $63,7 \%$ pelo microcomputador, $16,4 \%$ via tablet, $11,3 \%$ pela televisão e menos de $1 \%$ por outro equipamento eletrônico. Cerca de 33,4\% dos usuários da Internet utilizaram apenas o celular como forma de acesso, 4,4\% apenas o microcomputador, $0,3 \%$ apenas o tablet e $0,1 \%$ somente a televisão" (Agência IBGE notícias, 2018).

Isso significa que os smartphones constituem dispositivos usados de forma predominante para acesso à Internet, em detrimento de microcomputadores, por exemplo. Alguns problemas de ordem técnica podem ser associados ao uso da Internet pelo celular para ter acesso a conteúdo de cursos superiores veiculados na modalidade EaD, dentre eles: grande parte dos celulares não possuem memória suficiente para baixar os aplicativos das plataformas digitais, bem como dos arquivos das aulas; nem todos os pacotes de dados ou planos de Internet disponíveis para uso através do celular dão conta de transmissões por videoconferências.

Adicionalmente, a PNAD Contínua TIC 2016 também relatou que das 63,4 milhões de pessoas com 10 anos ou mais de idade que não utilizaram a Internet, 37,8\% não sabiam usar e 37,6\% alegaram falta de interesse, enquanto 14,3\% não acessaram por considerar o serviço caro (Agência 
IBGE notícias, 2018). Nesse contexto, cumpre ressaltarmos que há dificuldades de implementação da EaD no Brasil por fatores como o acesso à Internet e, quando ocorre esse acesso, os equipamentos eletrônicos utilizados para tal. Também pode-se citar a resistência de muitas instituições e docentes para a operacionalização dessa modalidade de ensino e o uso das tecnologias, de maneira geral, indo na contramão do acolhimento da sociedade no que concerne ao uso das tecnologias na educação. Sendo assim, na perspectiva de Behrens (2015, p. 407):

Percebe-se que a tecnologia tem sido cada vez mais acolhida pela população em geral, por meio da telefonia celular, laptop, Tablets, TV a cabo, computadores, entre outros recursos, para realizar procedimentos cotidianos. Os alunos, em função da resistência de alguns professores, ainda não têm encontrado nas instituições de educação superior procedimentos pedagógicos que utilizem esta tecnologia para realizar uma aprendizagem mais significativa e que os prepare para vida. A tecnologia hoje é uma realidade presente na sociedade e este é um fato que não pode mais passar despercebido pelos professores nos meios acadêmicos. (BEHRENS, 2015, p. 407)

Na perspectiva da referida autora, o uso das tecnologias deve ser aliado ao processo de ensino e aprendizagem, não cabendo mais posturas tradicionais de resistência à EaD por parte de alguns docentes, uma vez que aquela faz parte das novas relações de interação e educacionais em que a sociedade está inserida. Nesse contexto, o uso das TDIC's se apresenta por meio de propostas metodológicas inovadoras que alcançam uma maior quantidade de discentes e, especialmente nesse momento pandêmico, possibilita a continuidade das aulas, mantendo o calendário acadêmico de diversas IES.

De acordo com os ensinamentos de Behrens (2015), as tecnologias digitais já estão presentes nas relações de trabalho, negócios e diversão, podendo, também, adentrar no campo educacional, para tornar mais significativa a aprendizagem dos alunos. Considerando a suspensão das aulas nas diversas IES, devido à pandemia da Covid-19, destacamos a potencialidade que as tecnologias desempenham nesse processo, viabilizando a continuidade das aulas moldadas à um novo formato - o ensino remoto.

Na perspectiva de Soares (2009), um fator que dificulta a adaptação, por parte dos docentes, às novas metodologias de ensino e aprendizagem se dá por não haver uma formação de professores universitários específica que contemple os saberes da docência, especificamente no que concerne à condução das aulas nas suas múltiplas possibilidades, o que inclui o modelo EaD.

Apesar do despreparo para lidar com esse cenário, mas visando à adequação a novos tempos, pode-se observar que diversas IES adotaram a modalidade remota de ensino para atender ao momento de excepcionalidade, notadamente adequando sua estrutura institucional, oferecendo auxílios de pacote de dados para estudantes carentes (no caso da IES públicas) e ofertando componentes curriculares nesse novo formato para mitigar os prejuízos proferidos aos seu alunado.

Por fim, destacamos que, na perspectiva de Moran (2017), as tecnologias permitem o registro e a identificação dos processos de ensino e aprendizagem por todos os envolvidos, possibilitando sistematizar progressos e dificuldades para que sejam tomados novos rumos para o ensino. Ainda conforme o referido autor, a combinação das metodologias ativas aliadas às 
inovações tecnológicas é considerada uma estratégia para a inovação pedagógica nos seus diversos níveis formais de ensino.

\section{CONSIDERAÇÕES FINAIS}

Na esteira de discussão sobre as metodologias ativas e a EaD, constatamos a importância do uso e aplicabilidade dessa modalidade de ensino, em especial, devido à suspensão das aulas presenciais decorrente da pandemia da Covid-19, objetivando-se a mitigação dos prejuízos ocasionados aos discentes, que ficaram sem aulas.

Entretanto, é preciso refletir sobre as condições de desigualdade de acesso a serviços de Internet, microcomputadores com acesso à internet e dispositivos eletrônicos em todas as regiões do Brasil, de acordo com os dados do IBGE referentes às PNAD 2015 e PNAD Contínua TIC 2016, que possibilitem o acompanhamento, a participação e o desempenho das atividades síncronas (aulas e avaliações) e assíncronas (conteúdo em texto, vídeo, hiperlinks, esquemas e atividades). Tais dificuldades, aliadas à sobrecarga de trabalho gerada pela criação e disponibilização de conteúdo e demais tarefas relacionadas ao andamento das disciplinas de forma remota e à condição psicológica dos docentes de ensino superior, em virtude da maior pressão por adaptabilidade a esse modelo de ensino; faz com que verifiquemos que a implementação do EaD no Brasil envolve grandes desafios.

Por esse motivo, nota-se que, devido à célere expansão da Covid-19, muitas IES não tiveram tempo hábil para adequar a sua estrutura institucional, fazendo com que fossem criados, às pressas, um plano de contingência institucional visando dar continuidade aos seus calendários acadêmicos.

Para responder à pergunta "Que oportunidades de aprendizagem os professores podem propor para o período de ensino remoto?", levantou-se a necessidade dos docentes de ensino superior em propor um modelo de formação online, envolvendo atividades síncronas e assíncronas, que gerem engajamento dos estudantes nos processos de ensino e aprendizagem, e que, para atingir esse objetivo, contemplem as três dimensões do engajamento acadêmico no ensino remoto: afetiva, cognitiva e comportamental.

Com a finalidade de responder à pergunta "Que oportunidades de aprendizagem os professores podem propor para o período de ensino remoto?", verifica-se que é indubitável que a utilização das metodologias ativas no ensino a distância impacta o modo pelo qual o estudante vivencia o Ensino Superior, através da ressignificação do seu modo de aprender, fomentando a sua autonomia e o desenvolvimento do pensamento crítico, reflexivo e analítico.

É nessa perspectiva que as metodologias ativas e o ensino na modalidade EaD estão interligados, intrinsecamente, por meio do oferecimento de estratégias que estabelecem maior flexibilidade de tempo e espaço aos estudantes, e que, adicionalmente, possibilitam que os docentes desenvolvam aulas em plataformas digitais, com a mesma qualidade dos encontros presenciais tradicionais.

Por fim, percebendo a necessidade de ressignificação abrupta das práticas pedagógicas desenvolvidas por diversas instituições de ensino, apontam-se algumas estratégias de aplicação de metodologias de ensino híbrido, visando a adaptação dos momentos de aula que, num contexto usual, seriam presenciais, para salas de aula virtuais, apropriando-se para isso das TDIC's. Essa 
adaptação permite dar continuidade aos cursos e, certamente, apresentam-se como alternativas significativas no que tange ao desenvolvimento integral do estudante de nível superior.

\section{REFERÊNCIAS}

Behrens, M. A. (2015). Paradigma da complexidade na prática pedagógica dos professores universitários: inovações epistemológicas e tecnológicas para ensinar e para aprender. In: CAVALCANTE, Maria Marina Dias et al. Didática e prática de ensino: diálogos sobre a escola, a formação de professores e a sociedade. Fortaleza: Editora da UECE, p. 1-19. Disponível em:http://www.uece.br/endipe2014/ebooks/livro4/11.\%20INOVAÇÕES\%20NAS\%20PRÁTICAS \%20PEDAGÓ GICAS\%20NA\%20EDUCAÇÃO\%20SUPERIOR.pdf. Acesso em 13/06/2020.

Bergman, J.; Aaron, S.. (2017). Sala de aula invertida: uma metodologia ativa de aprendizagem. Tradução: Afonso Celso da Cunha Serra. 1. Ed. Rio de Janeiro. LTC.

Berbel, N. A. N. (2011, jan./jun.). As metodologias ativas e a promoção da autonomia de estudantes. Ciências Sociais e Humanas, Londrina, 32(1), p. 25-40.

Carey, Kevin (2020). Everybody Ready for the Big Migration to Online College? Actually, No. Disponível em: https://www.nytimes.com/2020/03/13/upshot/coronavirus-online-collegeclasses-unprepared.html. Acesso em: 08 de jun.de 2020.

Côrte Vitória, Maria Inês.; CASARTELLI, Alam.; RIGO, Rosa Maria; COSTA, Priscila Trarbach (2018). Engajamento acadêmico: desafios para a permanência do estudante na Educação Superior. Educação, v. 41, n. 2, 262-269.https://doi.org/10.15448/1981-2582.2018.2.27960

Instituto Brasileiro de Geografia e Estatística (IBGE)(2016). Pesquisa nacional por amostra de domicílios: síntese de indicadores 2015. Coordenação de Trabalho e Rendimento. Rio de Janeiro: IBGE. 108p. Disponível em: https://biblioteca.ibge.gov.br/visualizacao/livros/liv98887.pdf.

Instituto Brasileiro de Geografia e Estatística (IBGE) (2018). Agência IBGE Notícias. PNAD Contínua TIC 2016: $94,2 \%$ das pessoas que utilizaram a Internet o fizeram para trocar mensagens. Disponível em: https://agenciadenoticias.ibge.gov.br/agencia-sala-deimprensa/2013-agencia-de-noticias/releases/20073-pnad-continua-tic-2016-94-2-daspessoas-que-utilizaram-a-internet-o-fizeram-para-trocar-mensagens. Acesso em 11 de julho de 2020.

Melo Júnior, P. M. R.; Maia, S. M. A. S.; Cunha, R. S. C.; Espíndola Júnior, E.; Bollela, V. R. (2018). Sala de aula invertida para o ensino do conteúdo abertura coronária em Endodontia. Revista da ABENO, 18 (2), p. 182-191.

Moffett, J. (2015). Twelve tips for "flipping" the classroom. Med. Teach, v. 37, n. 4, p. 331-336. 
Moran, J. (2017). Metodologias ativas e modelos híbridos na educação. In: YAEGASHI, Solange e outros (Orgs). Novas Tecnologias Digitais: Reflexões sobre mediação, aprendizagem e desenvolvimento. Curitiba: CRV, p.23-35. Disponível em: http://www2.eca.usp.br/moran/wpcontent/uploads/2018/03/Metodologias_Ativas.pdf. Acesso em 13 de junho de 2020.

Sachetti, L. R. D. (2017). Análise da experiência de sala de aula invertida em curso de matemática básica para ingressantes em cursos de um centro de engenharias. Disponível em:https://repositorio.ufsc.br/xmlui/bitstream/handle/123456789/182300/Artigo_TCC_Lucia na_final.pdf?sequence=1\&isAllowed=y>. Acesso em 13 de junho de 2020.

Soares, S. R. (2009). Pedagogia universitária: campo de prática, formação e pesquisa na contemporaneidade. In: Nascimento, AD., and Hetkowski, TM., orgs. Educação e contemporaneidade: pesquisas científicas e tecnológicas [online]. Salvador: EDUFBA, p. 93-108. Disponível em: http://books.scielo.org/id/jc8w4/pdf/nascimento-9788523208721-05.pdf. Acesso em 13 de junho de 2020.

Staker, Heather; HORN, Michael B. (2012). Classifying K-12 Blended Learning.Disponível em: http://files.eric.ed.gov/fulltext/ED535180.pdf>. Acesso em 13 de junho de 2020.

Unesco (2020). Webinar Covid-19: um novo mundo para professores, trabalhadores da linha de frente da educação. 13 de mar 2020. Disponível em: https://pt.unesco.org/news/webinarCovid-19-um-novo-mundo-professores-trabalhadores-da-linha-frente-da-educacao. Acesso em: 08 de junho de 2020.

Valente, José Armando. (2014). Blended learning e as mudanças no ensino superior: a proposta da sala de aula invertida. Educar em Revista, n. 4, p.79-97.

\section{COMO CITAR ESTE ARTIGO:}

Palmeira, R. L., Silva, A. A. R. da, Ribeiro, W. L. (2020). As metodologias ativas de ensino e aprendizagem em tempos de pandemia: a utilização dos recursos tecnológicos na Educação Superior. Holos. 36(5), 1-12.

\section{SOBRE OS AUTORES}

\section{R. L. PALMEIRA}

Mestre em Políticas Públicas, Gestão e Avaliação da Educação Superior (MPPGAV/ UFPB), é 'tecnólogo com graduação em Sistemas para Internet, pelo Centro Universitário de João Pessoa (UNIPE). Tem experiência na área de Ciência da Computação, com ênfase em Arquitetura de Sistemas de Computação, Engenharia de software, gerenciamento e manutenção em equipamentos de Informática, equipamentos de laboratório e hospitalares. Atualmente é Servidor público Federal trabalhando na área de Tecnologia da Informação como Coordenador de TI na Escola Técnica de Saúde da UFPB (ETS). É pesquisador no Grupo de Pesquisa " MAPA DA EDUCAÇÃO SUPERIOR NA PARAÍBA: ANÁLISE DO SETOR PÚBLICO E PRIVADO. Projeto aprovado no Edital/Chamada: MCTI/CNPq no 01/2016 -UNIVERSAL, processo número: 424718/2016-2, O projeto pretende desenvolver uma investigação que objetiva mapear a educação superior no Estado da Paraíba, como um esforço de visão de totalidade, a partir de três dimensões, a saber: Institucional - que compreende a estrutura funcional da instituição a partir da oferta de cursos por áreas de conhecimento, matrículas e conclusão, demandas reprimidas, política de financiamento para o acesso e permanência; GRUPO DE 
ESTUDOS E PESQUISA SOBRE A CONDIÇÃO DISCENTE , objetivos discutir, problematizar e entender a relação entre o estudante e as instituições de ensino no Brasil, com vistas a contribuir com a criação de um novo modelo educacional mais democrático, participativo e inclusivo.. E-mail: astecapb@ hotmail.com ORCID ID: http://orcid.org/0000-0002-5396-5178

\section{A. A. R. DA SILVA}

Graduada em Engenharia Química pela Universidade Federal da Paraíba (2016), Especialista em Engenharia de Segurança do Trabalho pelo Centro Universitário de João Pessoa (2018), Mestra em Engenharia de Produção pela Universidade Federal da Paraíba (2019). Durante a graduação teve a oportunidade de estagiar na empresa Incoplast Embalagens do Nordeste Ltda., atuando no setor de Galvanoplastia e oferecendo suporte aos setores de qualidade, produção e meio-ambiente, por meio do desenvolvimento de pesquisas. De fevereiro a maio de 2019 atuou como docente das disciplinas de matemática e ciências de duas turmas de 50 ano do Ensino Fundamental I da Escola Municipal Professora Laura Florêncio, no município de Caruaru (PE). De maio até dezembro de 2019 atuou como docente da disciplina de matemática em duas turmas de 6o ano e duas turmas de 7ㅇ ano do Ensino Fundamental II da Escola Municipal Presidente Kennedy, no município de Caruaru (PE). Atuou como autora de conteúdo da disciplina Engenharia de Métodos do curso superior de Engenharia de Produção pela DP CONTENT. Tem atuado como professora autora para produção autônoma de conteúdo para a Lekto Educacional, colaborando com a criação de cards, que consistem em atividades voltadas para o desenvolvimento de habilidades e competências socioemocionais de crianças, adolescentes e jovens em idade escolar. Também tem atuado como autora de conteúdo para o programa de formação em Segurança do trabalho, voltado para as Normas Regulamentadoras no 5, nㅇ 6, no 10 e nㅇ 20, de responsabilidade da Delinea Tecnologia Educacional. Atualmente é Professora Tutora de Engenharia na Descomplica, compondo o Núcleo de Qualidade Acadêmica, cujo foco de atuação é o aperfeiçoamento e a melhoria contínua dos conteúdos dos Cursos de Pós Graduação da instituição de ensino. E-mail: andrezza.ars@gmail.com

ORCID ID: http://orcid.org/0000-0002-6569-5515

\section{W. L. RIBEIRO}

Mestre em Políticas Públicas, Gestão e Avaliação da Educação Superior na Universidade Federal da Paraíba UFPB (2017-2018), Especialista em Educação em Direitos Humanos pela UFPB (2014-2015) e graduado em Direito pelo Centro Universitário de João Pessoa - UNIPÊ - (2009-2013). Atualmente é Servidor técnicoadministrativo da Universidade Federal da Paraíba (UFPB), lotado no Centro de Educação (CE). Tem experiência na área de Direito, notadamente na área de Direito Público. É Pesquisador no Grupo de Pesquisa em Avaliação da Educação Superior - GAES, cadastrado no CNPq e tendo como líder a Profa. Dra. Maria das Graças Gonçalves Vieira Guerra, que abarca investigações do campo na área de avaliação da educação superior, perpassado pelas políticas públicas, gestão e práticas educativas.. Atua, principalmente, nos seguintes temas: Direitos Humanos, Direito Previdenciário, Direito Constitucional, Direito Administrativo e Políticas Públicas.. E-mail: wagnerleiteribeiroadv@gmail.com

ORCID ID: http://orcid.org/0000-0003-2495-1030

Editor(a) Responsável: Leandro Costa Pareceristas Ad Hoc: LENINA SILVA E KALYANE OLIVEIRA 


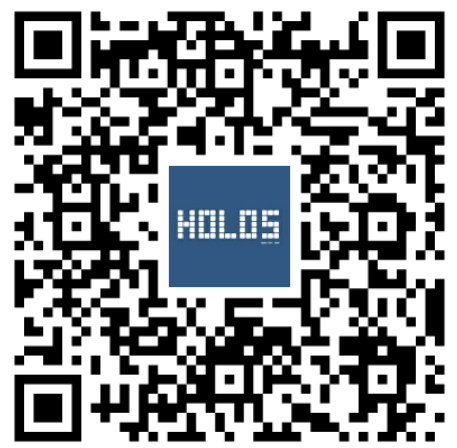

